\title{
0 contato entre português e polonês como língua de imigração: uma descrição acústico-articulatória de /I/ pós-vocálico
}

\author{
Giovana Ferreira-Gonçalves ${ }^{1}$ \\ Aline Rosinski ${ }^{2}$ \\ Programa de Pós-graduação em Letras, Universidade Federal de Pelotas, Pelotas, Rio Grande do Sul, Brasil
}

Resumo: Neste trabalho, são apresentados dados de produção oral, os quais evidenciam de que forma o polonês como língua de imigração manifesta-se no português como língua majoritária. O objeto de análise consiste em produções da lateral /// em posição pósvocálica, realizadas por sujeitos bilíngues que constituem uma comunidade de origem migratória. Pela caracterização do segmento, busca-se evidenciar como a utilização da língua de imigração é capaz de gerar uma constituição linguística única em seus falantes. Para a análise, é realizada uma exploração qualitativa, apoiando-se em critérios de análise acústica de registros orais e de análise articulatória de imagens ultrassonográficas. Os resultados apontam que a consoante de fato assume características bastante distintas das que são observadas nas formas consideradas padrão do português brasileiro. Assim, a constituição linguística diferenciada, refletida neste estudo, nas produções de ///, sustentase pela utilização do polonês como língua de imigração pelos indivíduos da comunidade.

Palavras-chave: Línguas de imigração; Polonês; Consoante líquida lateral.

Abstract: In this article, we present oral production data that show how Polish as an immigrant language manifests itself in Portuguese as a majority language. The object of analysis is the lateral /// in postvocalic position produced by bilinguals from a community of immigrant origin. By characterizing the segment, we sought to show how the use of the immigrant language can lead to a unique linguistic constitution in its speakers. A qualitative exploration was carried out, based on criteria of acoustic analysis of speech recordings and articulatory analysis of ultrasound images. The results show that the consonant actually takes on quite different characteristics from those observed in the forms considered standard in Brazilian Portuguese. The different linguistic constitution, in this study reflected in the productions of $/ \mathrm{I} /$, is maintained by the use of Polish as an immigrant language by the individuals in the community.

Keywords: Immigrant languages; Polish; Liquid lateral consonant.

\footnotetext{
${ }^{1}$ Doutora em Letras (Pontifícia Universidade Católica do Rio Grande do Sul), Universidade Federal de Pelotas. Orcid: https://orcid.org/0000-0002-3237-0255. E-mail: giovanaferreiragoncalves@gmail.com.

${ }^{2}$ Mestra em Letras (Universidade Federal de Pelotas). Orcid: https://orcid.org/0000-0001-6229-9683. E-mail: rosinskivieira@gmail.com.
} 


\section{Considerações iniciais}

O espaço das línguas de imigração vem diminuindo a cada nova geração nas comunidades hoje constituídas pelos descendentes de imigrantes chegados ao Brasil no século XIX. O estigma que recai sobre essas línguas é um dos principais motivos, o que é apontado em estudos como os de Oliveira (2000), Altenhofen (2004) e Frosi, Faggion e Dal Corno $(2017)^{3}$.

Contudo, o uso da língua de imigração ainda é observado na fala de sujeitos bilíngues, embora haja uma frequência bem menor na utilização da língua minoritária quando comparada à língua majoritária. Há ainda vestígios da língua da imigração vistos na constituição linguística do falante, ou seja, nas características que podem ser observadas na língua majoritária e que advêm da língua de imigração. Com relação ao polonês, por exemplo, conforme Druszcz (1983), esses vestígios da língua de imigração podem ser encontrados em diferentes unidades gramaticais, como a sintaxe, a morfologia e a fonologia.

Um exemplo da sintaxe, de acordo com o autor, pode ser encontrado na ordem das palavras, uma vez que o polonês é uma língua sintética e o português uma língua analítica assim, no polonês, com a utilização de declinações, a ordem das palavras não apresenta relevância para determinação das funções sintáticas, ao contrário do português. A produção de frases com a ordem indireta das palavras pode, portanto, ser mais facilmente encontrada na fala de bilíngues: "Uma friage peguei.", "Canal 4 passei.", "Pr'a vila foi." (DRUSZCZ, 1983, p. 86-87).

Com relação à segunda, isto é, à morfologia, morfemas poloneses podem ser encontrados em produções de verbos no infinitivo, bem como para marcar as diferentes pessoas verbais: "kobrowac' - cobrar", "fojsowac' - cortar com foice" e "lasowac' - laçar", dentre outras (DRUSZCZ, 1983, p. 90).

É exatamente no que concerne à terceira, ou seja, à fonologia, ou ainda, aos aspectos fonéticos-fonológicos, que o presente trabalho discorrerá. Assim, serão apresentadas características específicas do português influenciado pelo polonês como língua de imigração, tendo por base análises de dados de produção oral. Como objeto de análise, serão descritos aspectos da consoante líquida lateral ///, produzida em posição pós-vocálica - como nas palavras caldo e sinal - por sujeitos bilíngues que compõem uma comunidade de descendentes de imigrantes poloneses.

Um primeiro olhar sobre os dados, considerando resultados quantitativos, indica que o padrão de produção do segmento, realizado por bilíngues, diferencia-se do que é observado na produção de monolíngues. O detalhamento fonético-fonológico, contudo, propicia descrever as produções não como simples resultados da influência de uma língua sobre a

\footnotetext{
${ }^{3}$ Os estudos citados, diferentemente do que se apresenta neste artigo, referem o estigma atribuído às línguas de imigração tendo por base outros aspectos que não apenas os linguísticos (lexicais, fonológicos, morfológicos, por exemplo). Os dados que revelam a estigmatização das línguas de imigração são baseados em relatos dos próprios falantes dessas línguas, do seu posicionamento em relação à utilização dessas línguas minoritárias em ambientes diversos - trabalho, escola, contexto familiar, por exemplo.
} 
outra. Por meio do detalhamento, identificam-se formas orais de constituição singular dos bilíngues, resultantes do uso de uma língua minoritária e, também, do uso da língua majoritária, mas em uma comunidade específica. Ou seja, a caracterização das produções desses sujeitos não se encontra em qualquer outro contato entre polonês e português, como, por exemplo, quando a língua polonesa é aprendida como língua estrangeira. É preciso que haja o contato entre as duas línguas coexistentes na comunidade, somado ao fato de o polonês ser língua de herança. O indivíduo, portanto, constitui-se, ao longo de sua vida, como falante dessas línguas, vindo a produzir as formas que foram caracterizadas neste estudo.

\section{Língua de imigração como língua minoritária}

O processo migratório iniciado no final do século XIX, no qual povos dos continentes europeu e asiático, principalmente, deslocaram-se para o Brasil em busca de melhores condições de vida, acrescentou, às regiões onde eles se instalaram, aspectos da sua cultura, trazidos e conservados pelas comunidades de imigrantes como forma de manter vivos os traços de suas origens. Dentre os aspectos culturais que caracterizam um povo, está a língua do país que foi deixado para trás, cuja conservação buscou-se por meio de sua utilização no dia a dia das comunidades de imigrantes.

Conforme Spinassé (2006), conceituar as línguas de imigração como sendo línguas implantadas em solo brasileiro por imigrantes e não línguas de todo estrangeiras é uma tarefa difícil, tendo em vista que essa conceituação deve ser entendida e aceita pelas comunidades de fala e, também, por falantes externos.

A língua de imigração não pode ser caracterizada como língua estrangeira no momento em que é identificada como língua materna de indivíduos nascidos em território nacional. Porém, ela também não é, na maioria das vezes, caracterizada como uma das línguas mais faladas em um país. A língua de imigração é, dessa forma, originária de um outro país, mas, ainda assim, é a primeira língua de muitos falantes não estrangeiros. Observando esses aspectos, pode-se entender que as línguas trazidas por imigrantes europeus ao Brasil, há pouco mais de cem anos, constituem-se como línguas minoritárias.

Também, faz-se necessário apontar que as línguas de imigração não são, em geral, dominadas em todas as habilidades pelos falantes das comunidades, ainda que, para alguns, esta língua possa ser considerada língua materna. Isso acontece pelo fato de sua transmissão se dar, essencialmente, pela oralidade de geração para geração. Assim, o domínio escrito dessas línguas só poderia acontecer por meio do ensino, em escolas locais, aos moradores das comunidades. Sabe-se, contudo, que o ensino das línguas de imigração nas escolas foi banido no período nacionalista - Era Vargas -, o que fez com que, em muitas comunidades, como a de Costa do Arroio Grande, localizada no município de Dom Feliciano, Rio Grande do Sul comunidade cujos dados são analisados neste estudo -, o ensino formal da língua de imigração não mais voltasse a ser aplicado. 


\section{O polonês como língua de imigração em meio ao português como língua majoritária}

Dentre as diversas línguas de imigração chegadas em território brasileiro, vindas ou não do continente europeu, está o polonês. Nos estados da região Sul do país, é bem conhecida, também, a instalação de imigrantes italianos e alemães. É possível identificar, ainda, colônias originadas por russos e ucranianos, por exemplo. Todos esses grupos de imigrantes, portanto, trouxeram consigo suas línguas, cuja manutenção foi utilizada como forma de não esquecer de suas origens.

No entanto, os números de imigrantes de diferentes origens não foram distribuídos de forma equilibrada nos três estados da região. Sabe-se, por exemplo, que o estado do Paraná concentrou o maior número de imigrantes vindos da Polônia, como relembram Kawka (1982), Druszcz (1983) e Ferraz (2007). Dessa forma, ao ter-se como referência a língua polonesa de imigração, entende-se que sua manutenção, por conta do status adquirido pela língua, seja ele linguístico, social ou econômico, aconteceu e vem acontecendo de formas diferentes nas colônias de origem imigratória no Paraná e no Rio Grande do Sul.

No estado do Paraná, o número maior de colônias e, consequentemente, de falantes do Polonês permitiu a sobrevivência da língua, tendo como motivador o aspecto demográfico, citado por Ferraz (2007, p. 67). Entende-se, portanto, que, no Rio Grande do Sul, por outro lado, a língua majoritária - o português - possa ter encontrado mais espaço para adentrar na comunicação das comunidades polonesas em relação ao que se vê no Paraná, onde a língua de imigração passa a não ser a única utilizada, mesmo no espaço familiar.

Apesar das menores probabilidades de conservação do polonês como língua de imigração em comunidades do Rio Grande do Sul, aliado ao já conhecido estigma vinculado às línguas de imigração, detalhes fonético-fonológicos observados no falar dessas comunidades indiciam, ali, a presença do polonês.

Ao deixarem de utilizar a língua com seus filhos, alguns descendentes dos imigrantes buscam, na verdade, apagar um dos aspectos que consideram negativos, decorrentes de sua origem. A estigmatização e o distanciamento que já há entre as gerações mais jovens e os imigrantes que chegaram ao Brasil podem fazer com que, conforme Spinassé (2008), os descendentes das últimas gerações já não consigam resgatar o sentido da cultura de seus antepassados na língua. No entanto, a autora afirma que uma língua mostra a identidade de um povo não somente pela perspectiva dos próprios falantes, mas pelo modo de ver do outro sobre o falante bilíngue.

Assim, estando presente a língua na comunidade, mesmo que minimamente, ainda que haja a tentativa de integração total do falante aos aspectos do país do qual já é natural, ele acabará sendo remetido à caracterização de seus antepassados. Desse modo, entende-se que, por mais que seja utilizada a língua majoritária, a constituição linguística do falante será, no mínimo, híbrida, pois as marcas da língua de imigração sempre poderão ser vistas no português. 
Por isso, estudos como os de Druszcz (1983), Mileski (2013; 2017), Rosinski e FerreiraGonçalves (2017), Rosinski (2019) e Ferreira-Gonçalves e Rosinski (2019) descrevem aspectos fonético-fonológicos do português de comunidades constituídas por descendentes de imigrantes poloneses e, por meio de detalhamento de produções orais, identificam particularidades do falar dessas comunidades. Chama-se a atenção, portanto, para o fato de haver, para esses grupos, uma caracterização própria e não-comparável a outros grupos linguísticos do Brasil, a qual é revelada e referida, nos estudos que a realizam, como sendo diferenciada, devendo ser conservada para que seja mantida a identidade enquanto comunidade de fala.

\section{Evidências fonético-fonológicas do uso do polonês como língua de imigração}

Estudos dedicados à observação de sons do português produzidos por falantes de comunidades de origem polonesa no Brasil têm identificado, para essas produções, características específicas que as diferem do padrão da língua majoritária nas produções dos indivíduos.

É possível que esses resultados possam ser vistos como um fator negativo ao considerar-se o estigma que falantes de línguas de imigração sofrem por apresentarem, na língua majoritária, marcas da língua minoritária, como pode ser constatado no estudo de Spinassé (2008). Contudo, é importante, ainda, indicar o valor que possui a composição linguística de falantes que constituem uma comunidade formada por descendentes de imigrantes. E, nesta atribuição de valor, inclui-se não apenas a língua de imigração utilizada por parte dos integrantes da comunidade, mas, também, o seu português, que possui aspectos próprios.

Dessa maneira, estudos que investigam os detalhes fonéticos de produções dessas comunidades permitem que a singularidade dos grupos de falantes seja posta à vista, com a finalidade de ressaltar o quanto a conservação da língua de imigração é importante para manter vivos os aspectos únicos das comunidades originadas pelos imigrantes.

Druszcz (1983), com base em dados de 46 informantes - coletados no município de Araucária, localizado no estado do Paraná, descreve influências geradas pelo polonês como língua de imigração nas produções dos sujeitos bilíngues, reportando dezenove processos que afetam vogais e consoantes. Dentre esses, destacam-se: (i) desnasalização ou redução da nasalização da vogal central, como em c[a]po, para campo e gr[a]de, para grande; (ii) realização de ditongo nasal como [õ], como nas palavras fog[õ] e fac[õ], para fogão e facão;

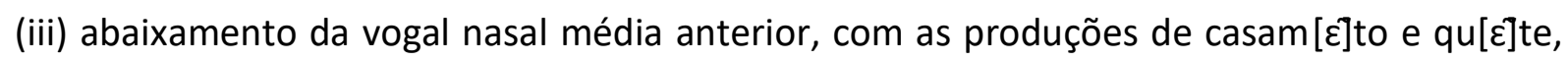
para casamento e quente; (iv) abaixamento da vogal oral média posterior, resultando em produções como [0]nibus e profess[0]r, para ônibus e professor; (v) alterações na qualidade dos segmentos róticos, com a produção de taps para alvos fricativos, como em cacho[r]o e ca[r]o, para cachorro e carro; (vi) realização de [n] em contextos de sequência [ni], em vocábulos como a[n]imal e ô[n]ibus, dentre outros. 
Estudos de Rosinski (2019) e Mileski (2017) observam duas classes de sons no português de comunidades de imigrantes localizadas no estado do Rio Grande do Sul. Colocase em evidência, aqui, a citação de estudos envolvendo comunidades do Rio Grande do Sul pelo fato de, neste estado, haver maiores dificuldades para a manutenção da língua polonesa de imigração em relação ao que é visto nas comunidades do Paraná, como já referido ao indicar-se o menor número de imigrantes poloneses instalados no estado gaúcho em relação ao número de imigrantes alemães e italianos (KAWKA, 1982; DRUSZCZ, 1983; FERRAZ, 2007). Assim, pelas investigações citadas, são identificados elementos sinalizadores do polonês mesmo em comunidades de imigrantes que, além de pequenas e sujeitas à perda da língua, quase foram, muitas vezes, sobrepostas por comunidades de outras origens, como as italianas ou alemãs, de acordo com o que sinalizam Weber e Wenczenovicz (2012).

O trabalho de Mileski (2017) caracteriza as vogais médias /e, o/ em posição tônica e pretônica, observando quando estes sons passam pelo processo de abaixamento, sendo produzidos como $[\varepsilon$, J] respectivamente. Os dados analisados pela autora são referentes aos municípios de Nova Prata, Nova Bassano, Vista Alegre do Prata e Áurea, produzidos por sujeitos bilíngues. Os resultados de base acústica atestaram que o processo de abaixamento dos sons vocálicos pode ser percebido em maior número de produções na fala de indivíduos que utilizam a língua de imigração com maior frequência. Dessa maneira, ao serem observados sons de apenas uma classe, vê-se o impacto da língua de imigração na forma como são produzidos na língua majoritária - o português.

O estudo de Rosinski (2019), analisando outra classe de sons, as líquidas laterais, tem seu foco na produção de /// em posição pós-vocálica, produzido no português, na fala de sujeitos da comunidade de Costa do Arroio Grande, pertencente ao município de Dom Feliciano. O som, nesse estudo, é produzido por sujeitos que utilizam ou não o polonês. $A$ caracterização de $/ \mathrm{I} /$, indicada pelos resultados, aponta que o som se diferencia da forma vista como padrão para o português - forma vocalizada - na fala da maioria dos bilíngues. Dentre os grupos dos bilíngues, também o resultado é variável: quanto mais presentes em ambientes de utilização do polonês os sujeitos estão (ambiente familiar, em grande parte dos casos), menor é o índice de vocalização identificado em suas produções de /I/.

Os resultados dos estudos citados indicam que, mesmo nas comunidades em que o uso do polonês decresce a cada geração, a constituição linguística dos falantes da língua de imigração fala por si, e aponta as particularidades do falar desses indivíduos, as quais são evidenciadas, muitas vezes, pelo detalhamento fonético de suas produções.

\section{Aspectos metodológicos}

Os resultados apresentados neste artigo, provenientes do estudo desenvolvido por Rosinski (2019), passaram por etapas de análise acústica e articulatória. Para a descrição do segmento lateral, foram observados dados de 12 sujeitos do sexo feminino, tendo entre 15 e 59 anos. Para a disponibilização dos dados, os sujeitos assinaram, antes da realização da 
coleta, um Termo de Consentimento Livre e Esclarecido, permitindo que suas produções orais fossem utilizadas nesta pesquisa. Assim, estando os indivíduos cientes do modo de utilização dos dados - sem indicação de identidade -, dava-se início à captação dos dados de fala.

Dentre o grupo de sujeitos selecionados, seis são bilíngues polonês-português e seis caracterizam-se como monolíngues, falantes de português. Para a caracterização dos sujeitos como bilíngues, houve o preenchimento de ficha individual, na qual foi apontada a frequência de uso da língua e as habilidades do sujeito para a utilização do polonês, feita por meio de autocaracterização ${ }^{4}$. Para serem considerados bilíngues, os sujeitos deveriam indicar, pelo menos, a compreensão e a produção oral da língua. O grupo bilíngue indicou uma utilização diária da língua de imigração, com exceção do sujeito B58, que indicou uma média mensal do uso da língua. Todos os sujeitos são habitantes da comunidade de Barra do Arroio Grande, localizada no interior do município de Dom Feliciano-RS.

Os dados acústicos foram obtidos com base em produções de fala espontânea, sem qualquer tipo de controle ou indicação de palavra a ser realizada. A gravação foi feita por meio de gravador digital modelo Zoon H4n. O tempo médio de fala espontânea foi controlado, com, aproximadamente, 15 minutos para cada sujeito ${ }^{5}$. Da produção espontânea, foram selecionadas as palavras que apresentavam realização do segmento alvo de análise. A seguir, no Quadro 1, podem ser observadas as produções de /// pós-vocálico nas palavras realizadas pelos sujeitos.

Quadro 1 - Palavras produzidas em fala espontânea por sujeitos bilíngues e monolíngues

\begin{tabular}{|c|c|c|c|}
\hline \multicolumn{2}{|r|}{ Bilíngues } & \multicolumn{2}{|r|}{ Monolíngues } \\
\hline $\begin{array}{c}\text { B16- } \\
1\end{array}$ & $\begin{array}{c}\text { sol, qualquer, normal, Miguel, legal, } \\
\text { especial, calcário }(3 x)\end{array}$ & M15 & qualquer (2x), difícil \\
\hline $\begin{array}{c}\text { B16- } \\
2\end{array}$ & almoço, alta, calça, tal $(4 x)$, voltava $(2 x)$ & M17 & $\begin{array}{l}\text { agricultor, agricultora, alça, difícil, final } \\
(2 x) \text {, fundamental, legal, natal, sol }\end{array}$ \\
\hline B49 & $\begin{array}{c}\text { alguma, alto, difícil, falta, fácil, galpão } \\
(2 x) \text {, natal, pessoal, saudável }(2 x) \\
\text { último }\end{array}$ & M44 & azul, falta, horrível, futebol (2x) \\
\hline B50 & $\begin{array}{l}\text { Elza (9x), hospital, mol, polva, qual, } \\
\text { volta }\end{array}$ & M46 & difícil, final, igual (2x), ilegal \\
\hline B58 & $\begin{array}{l}\text { Romilda, alto, Alvídia, colchão (4x), } \\
\text { culto (3x), difícil, final, sol (2x), Valnir, } \\
\text { voltando }\end{array}$ & M55 & $\begin{array}{l}\text { alta, solta, natural, fatal, difícil, coral } \\
(4 \mathrm{x}) \text {, cascavel, alto }(2 \mathrm{x})\end{array}$ \\
\hline
\end{tabular}

\footnotetext{
${ }^{4}$ Pelo fato de não haver a aplicação de nenhum teste de proficiência na língua polonesa, os próprios sujeitos indicaram, quando questionados, em quais habilidades apresentavam domínio da língua - produção, compreensão, escrita e leitura.

${ }^{5} \mathrm{O}$ tempo de produção de fala espontânea foi estabelecido como sendo de 15 minutos, levando em consideração as outras etapas de coleta das quais cada sujeito também participou: fala controlada - cujos dados não serão discutidos no presente trabalho - e coleta articulatória. O estabelecimento desse tempo de fala espontânea observou o conforto dos informantes, de modo a evitar a exaustão e, também, possíveis consequências na produção dos dados de fala nas etapas de coleta seguintes.
} 


\begin{tabular}{|c|c|c|c|}
\hline B59 & $\begin{array}{c}\text { Nilton (3x), alcanço, alguém (2x), } \\
\text { almoço (2x), anormal, assalto, calçado, } \\
\text { descalço, falso, maltrapilho, natal (2x), } \\
\text { sal }\end{array}$ & M59 & $\begin{array}{c}\text { Adulto (3x), analfabeto, final, mobral } \\
(3 \mathrm{x}), \text { sinal }\end{array}$ \\
\hline
\end{tabular}

Fonte: as autoras.

Os dados articulatórios são provenientes de produções de um informante bilíngue, feitas a partir de instrumento de nomeação de imagens, dada a maior dificuldade de registro de imagens articulatórias das produções: realizadas com o auxílio de equipamento ultrassonográfico modelo Mindray DP 6600, equipado com sonda micro-convexa, e de um capacete estabilizador dos movimentos da cabeça em relação à sonda. Os dados articulatórios aqui analisados foram coletados no Laboratório Emergência da Linguagem Oral (LELO) da Universidade Federal de Pelotas.

Para a apresentação sincronizada de aspectos acústicos e articulatórios, o detalhamento fonético-fonológico é realizado com base, nas duas etapas de análise, em dados de um mesmo sujeito. Dessa maneira, a mostra de especificidades articulatórias estará alinhada com as especificidades indicadas pela acústica.

Como ferramenta de análise acústica, é utilizado o software PRAAT, versão 6.0.20, o qual permite e visualização da forma de onda, um dos aspectos observados para identificação da lateral, e os valores dos formantes, os quais caracterizam o segmento como produzido na parte posterior ou na parte anterior do trato articulatório. Esta indicação é que possibilita classificar o segmento como mais velarizado (próximo ao padrão do PB) ou menos velarizado (próximo ao padrão do polonês). Os valores formânticos são extraídos, para análise dos segmentos líquidos laterais, do primeiro e do segundo formantes, posteriormente indicados como F1 e F2, respectivamente. Além da descrição dos valores dos formantes, para determinar o segmento como tendo uma produção mais anterior ou mais posterior, é calculada a diferença entre os valores de F1 e F2. Este método de caracterização da lateral é adotado por outros estudiosos que descrevem os aspectos de /I/, tais como Sproat e Fujimura (1993), Naraynan (1997) e Brod (2014).

A descrição acústica considera valores formânticos extraídos do ponto médio de produção do segmento, ou seja, o mais distante possível das bordas, que podem apresentar influências acústicas de segmentos circundantes, principalmente os sons vocálicos, ou seja, os chamados fenômenos coarticulatórios. É preciso indicar, também, que o ponto médio observado é localizado na metade da porção estável do segmento, ou seja, o período que se inicia após a transição entre a vogal e a lateral, como indicado na Figura 1. 
Figura 1 - Período de transição e fase estacionária da lateral pós-vocálica

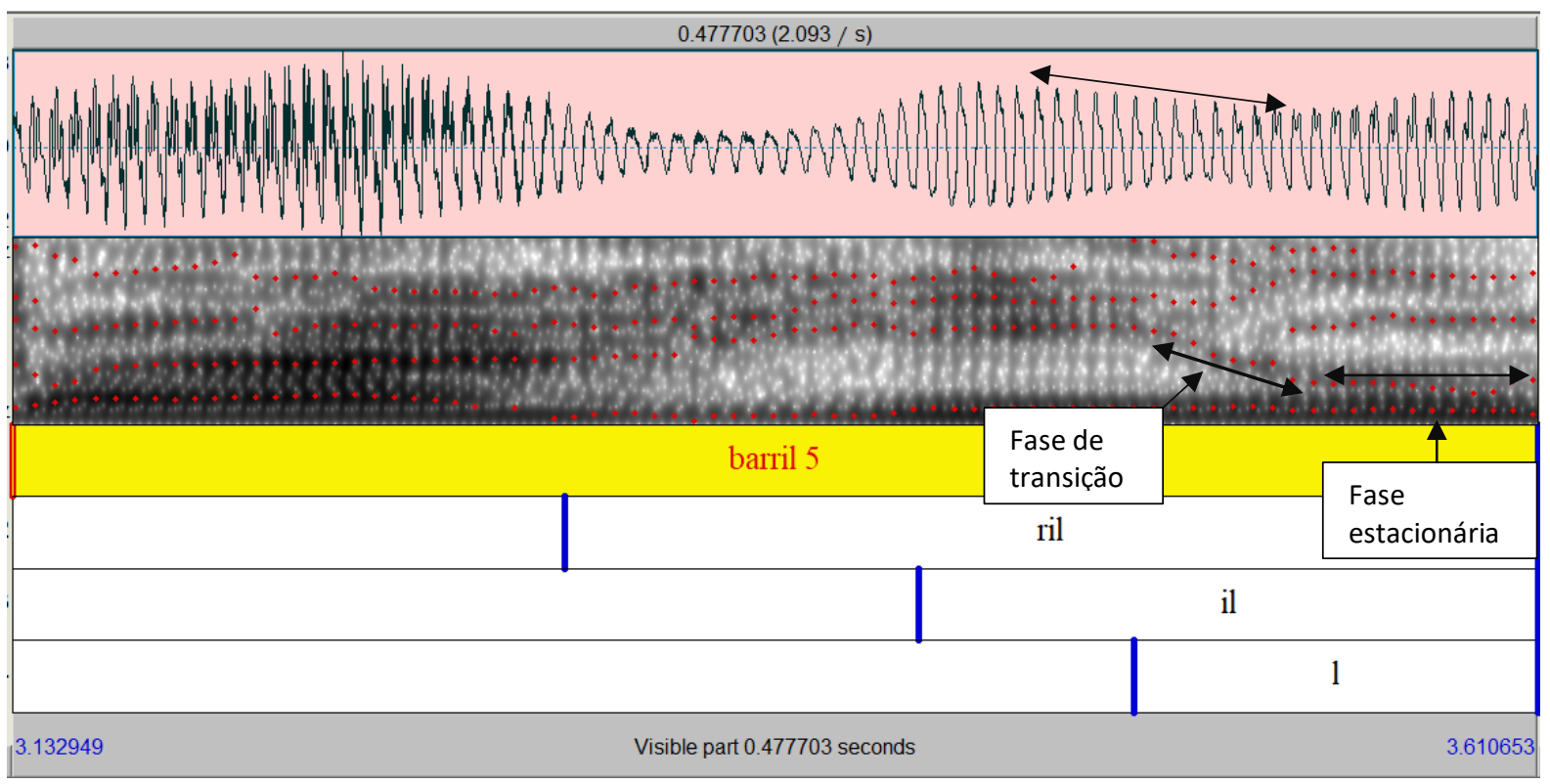

Fonte: as autoras.

Sons vocálicos costumam apresentar amplitude de onda maior do que sons líquidos, conforme apontamento de Silva (1996), ou, pelo menos na fase de transição, a amplitude da lateral em relação à vogal costuma diminuir. Por isso, produções de /I/ não vocalizadas podem apresentar o período de transição entre a vogal e a lateral, o qual reflete-se na queda da amplitude da onda e, também, na queda dos valores de formantes. Desse modo, ao término da redução gradual da amplitude de onda, associado ao fim da queda dos valores formânticos - especificamente de F2 -, entende-se, assim como em Turton (2017), que a vogal que antecede / $/ /$ já deixou de ser produzida.

Para a análise articulatória, utiliza-se o software AAA (Articulate Assistant Advanced), com o qual também foi realizada a coleta das imagens ultrassonográficas. A partir do software, são identificados os movimentos de obstrução da língua, ou seja, o ápice da produção da consoante, referido como movimento de maior magnitude. Por meio da identificação desse movimento, é que se determina uma produção como realizada na parte posterior ou na parte anterior do trato. Quando realizada na parte posterior, o movimento de maior magnitude será realizado com o dorso da língua, em direção ao véu palatino; ao ser realizado na parte anterior, o movimento de maior magnitude será o de ponta de língua, direcionada aos dentes ou alvéolos (RECASENS, 1995, 2004).

Desse modo, nas imagens ultrassonográficas, que permitem a visualização da língua em corte sagital, é realizado o traçado do articulador no frame que indica a constrição de maior magnitude durante a realização da lateral. Assim, pode-se definir o tipo de movimento realizado pela língua no momento em que a produção de /I/ atinge o seu ápice. Na Figura 2, é possível ver o desenho da borda da língua realizado por meio do AAA. 
Figura 2 - Demarcação das bordas da língua (traçado em vermelho) por meio do programa AAA

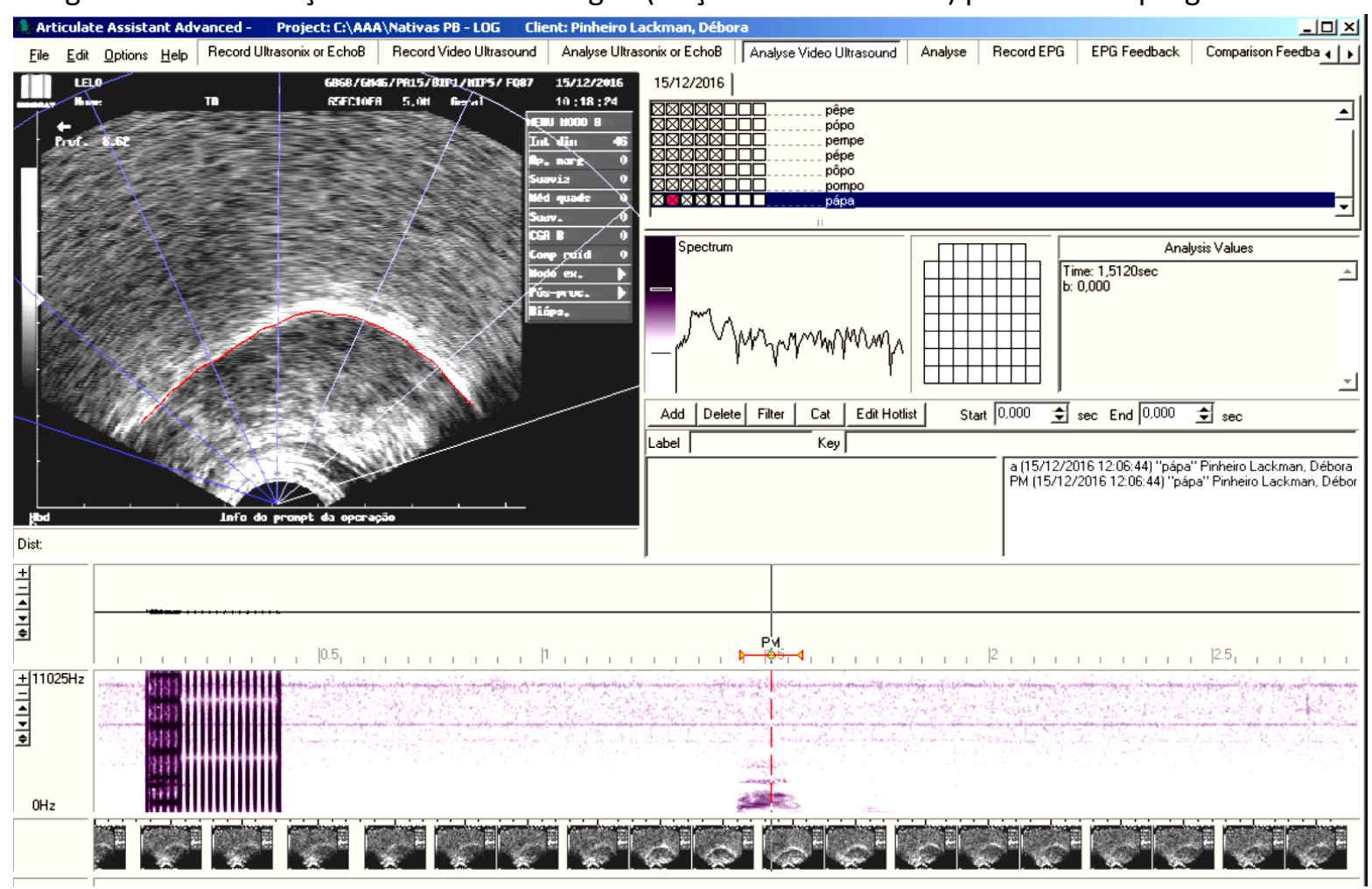

Fonte: Correa (2017, p. 96).

Realizado o traçado da borda da língua, pode-se, ainda, realizar plotagens (união dos traçados de bordas de língua em uma só imagem), comparando os movimentos do ápice de diferentes produções de um único sujeito. A comparação deve ser feita com ressalvas, no entanto, entre produções de dois sujeitos ou mais, já que a configuração do trato articulatório de cada indivíduo é única, ou seja, apresenta medidas diferentes que impossibilitam a comparação visual do comportamento dos articuladores.

Detalhamento acústico-articulatório de produções de /I/ por sujeitos bilíngues portuguêspolonês

A consoante lateral do português brasileiro, pertencente à classe dos segmentos líquidos, é investigada por diversos estudos, incluindo falantes de diferentes regiões e estados do país. Dentre estes estudos, pode-se citar os trabalhos de Quednau (1993), Silva (1996), Tasca (1999) e Collischonn e Quednau (2009). A escassez na descrição de aspectos fonéticofonológicos deste segmento torna-se visível quando se trata da sua produção em grupos de falantes de línguas de imigração de origem eslava, principalmente.

Em uma comunidade na qual prevalece o polonês como língua de imigração, como no presente estudo, a observação da produção da lateral foi feita tendo por base a caracterização que se apresenta, para o segmento, como padrão no português, a forma vocalizada, que é assim caracterizada desde Câmara Jr. (1970). 
A forma vocalizada para /// pós-vocálico, também apontada como a mais recorrente no português por Collischonn e Quednau (2009), caracteriza-se por uma articulação indicada como posterior. Assim, sua produção é feita, seguindo caracterização da Fonologia Gestual (doravante FonGest), com gesto de corpo de língua como sendo o mais proeminente na produção do segmento (NARAYANAN et al., 1997; RECASENS, 2004). Acusticamente, este segmento apresenta valores formânticos mais baixos, tendendo a uma aproximação das frequências de F1 e F2.

Diferentemente da caracterização observada no PB, no polonês, a lateral pós-vocálica é considerada um segmento anterior, sendo classificada como alveolar (SZREDER, 2013) tanto em posição pós-vocálica como em posição pré-vocálica. Dessa maneira, sua produção se dá com um gesto articulatório mais proeminente de ponta de língua, em direção à parte anterior do trato articulatório. Por parâmetros acústicos, a forma de realização de /I/ pós-vocálico no polonês tende a apresentar elevação do valor de $\mathrm{F} 2$, gerando distanciamento entre os valores do primeiro e do segundo formantes (RECASENS, 2004).

Levando em consideração que a FonGest observa o conceito de continuum (SPROAT; FUJIMURA, 1993; NARAYANAN et al., 1997), na realização dos gestos articulatórios, o segmento lateral não será necessariamente anterior ou vocalizado. Assim, quanto mais velarizado (com uma projeção do articulador para a parte posterior do trato), vê-se uma aproximação com a forma de produção identificada na vocalização; quanto menos velarizado (em que a língua, afastando-se do véu palatino, direciona-se para a parte anterior do trato), a caracterização aproxima-se do é visto quando a produção é alveolar (SPROAT; FUJIMURA, 1993).

Para a obtenção dos resultados, cada produção foi registrada como aproximando-se ou distanciando-se da classificação padrão do português. Produções de sujeitos da mesma comunidade e que não utilizam o polonês como língua de imigração foram comparadas às de sujeitos falantes de polonês, de forma a caracterizar, com maior precisão, a influência da língua de imigração nas produções.

Os resultados são observados a partir do que revela a análise acústica dos dados. Os valores formânticos distribuídos no Quadro 1 referem-se a uma classificação próxima de uma produção com maior velarização (próxima à produção padrão do português, a forma [w]) ou com menor velarização (próxima a uma produção alveolar, não padrão para a posição pósvocálica no português, a forma [l]). Quanto mais elevados os valores formânticos, mais distante está a produção de /// do que é comumente observado no português brasileiro. No Quadro 2, os sujeitos estão representados pelas esferas azuis e vermelhas, localizadas com base no valor das médias da diferença entre F2 e F1 de suas produções. 
Quadro 2 - Distribuição das produções de /I/ para sujeitos falantes e não falantes de polonês, com base nas diferenças acústicas entre F2 e F1

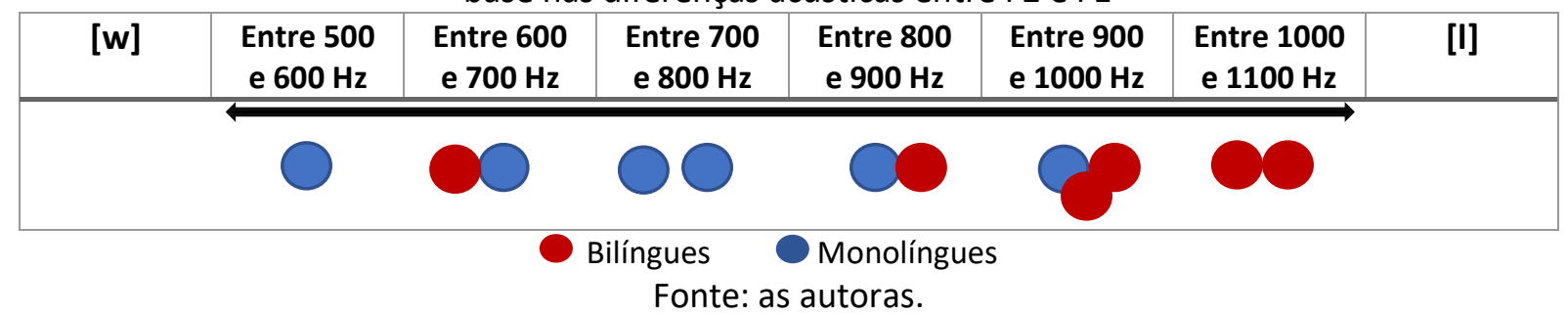

A análise quantitativa de produções dos dois grupos de sujeitos - falantes e não falantes de polonês - aponta uma tendência de afastamento do / $/$, produzido por bilíngues, da forma padrão no português. A distribuição dos resultados também indica que, apesar de variáveis, as produções dos monolíngues podem igualmente se distanciar do padrão esperado para a língua portuguesa. Os estudos de Quednau (1993) e Tasca (1999), nos quais analisouse a produção da lateral pós-vocálica em diferentes grupos de fala do estado do Rio Grande do Sul, também apontam uma produção diferente da forma vocalizada em regiões rurais e em que há a presença do bilinguismo, identificando uma realização velarizada e, até mesmo, alveolar. ${ }^{6}$

A fim de observar mais detalhadamente o que os resultados acústicos revelaram na produção de cada sujeito dos dois grupos - monolíngues e bilíngues -, destacam-se, no Quadro 3, os valores da média de diferença F2 - F1 das produções de /I/.

Quadro 3 - Valores de média de F2-F1 nas produções dos bilíngues e dos monolíngues

\begin{tabular}{|c|c|c|c|}
\hline Bilíngues (idade) & Diferença F2 - F1 (Hz) & $\begin{array}{c}\text { Monolíngues } \\
\text { (idade) }\end{array}$ & $\begin{array}{c}\text { Diferença F2 - F1 } \\
\text { (Hz) }\end{array}$ \\
\hline B16-1 & 612 & M15 & 859,6 \\
\hline B16-2 & 1025,1 & M17 & 759,7 \\
\hline B49 & 944,8 & M44 & 785,2 \\
\hline B50 & 945,3 & M46 & 927 \\
\hline B58 & 864,8 & M55 & 646,8 \\
\hline B59 & 1098,9 & M59 & 521 \\
\hline
\end{tabular}

Fonte: as autoras.

A partir da distribuição das produções para os dois grupos, observa-se a manifestação do uso da língua de imigração na classificação do segmento, com uma tendência à anteriorização nas produções bilíngues - maiores diferenças entre F1-F2.

A análise qualitativa dos dados também contribui para a compreensão da influência do polonês na produção de /// pós-vocálico, pois passa-se de macroevidências (dados numéricos) à visualização de microevidências.

\footnotetext{
${ }^{6}$ A caracterização da lateral nestes estudos, diferente do apresentado neste trabalho, não tem por base a observação do continuum de produção e, por isso, ao referir as formas velarizadas, determina-as como uma categoria de classificação.
} 
As produções de /I/ em final de sílaba na fala dos bilíngues, sob observação acústica, apresentam evidências que as distinguem da vogal antecedente, justamente por seu caráter não vocalizado. Algumas produções, como citado na seção Aspectos metodológicos, podem apresentar uma queda dos formantes, especialmente de F2, além da queda da amplitude de onda. Essas evidências podem ser vistas na produção da palavra culto (Figura 3).

Figura 3 - Representação acústica da palavra culto

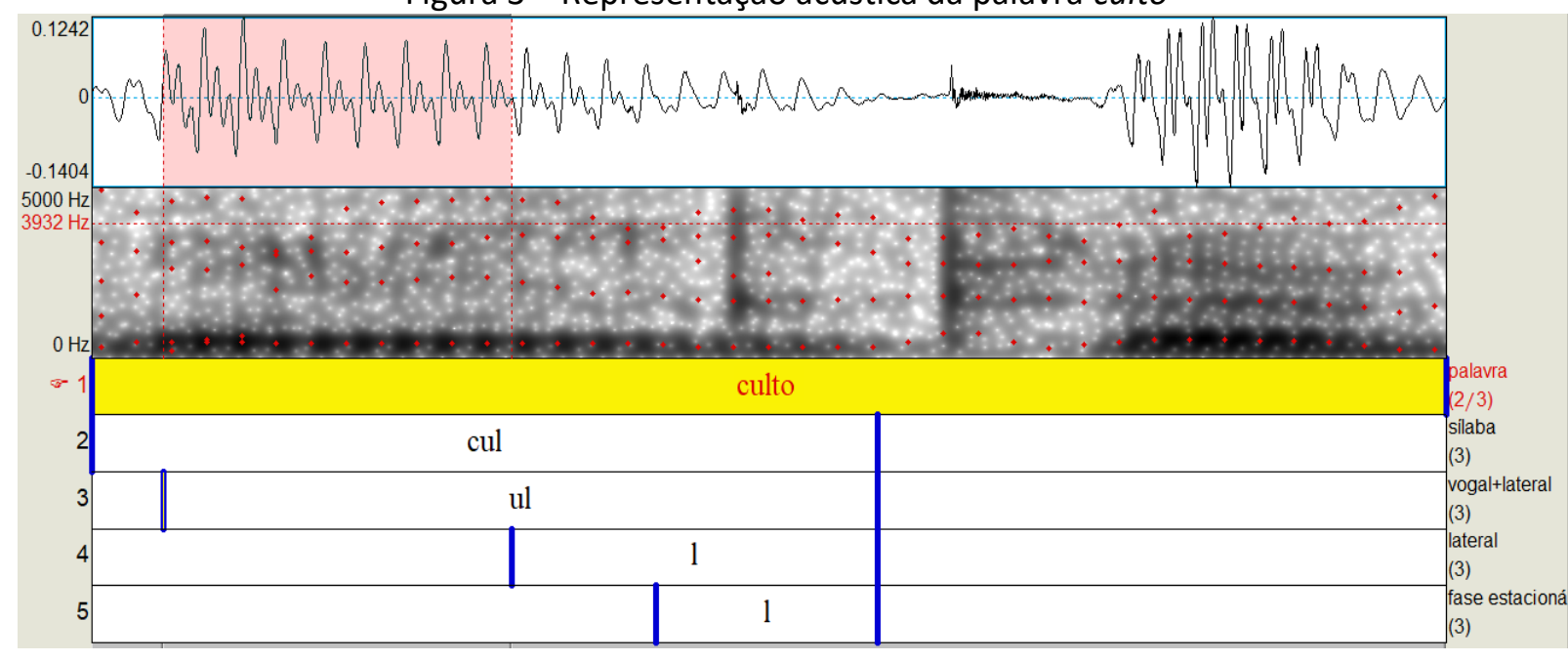

Fonte: as autoras.

A lateral produzida em culto, até mesmo por ser precedida de uma vogal alta - vogal [u] -, demonstra o período de transição da vogal para a lateral, com queda nos valores do segundo formante. Este indício é, também, auxiliado pela diferença de amplitude de onda entre vogal e lateral. A queda dos valores de F2 não diminui o seu distanciamento em relação a F1, confirmado pelos valores formânticos obtidos para a produção: $298 \mathrm{~Hz}$ para o primeiro formante e $1640 \mathrm{~Hz}$ para o segundo formante.

Como forma de complementação ao exemplo representado na Figura 3, é possível indicar a produção da palavra almoço, em que /// é antecedido pela vogal baixa [a]. Neste exemplo, novamente a lateral apresenta distinção clara da vogal que a antecede, desta vez, no entanto, não apresentando queda de F2 em relação à vogal, mas, sim, elevação de seus valores. Observe-se a Figura 4: 
Figura 4 - Representação acústica da palavra almoço

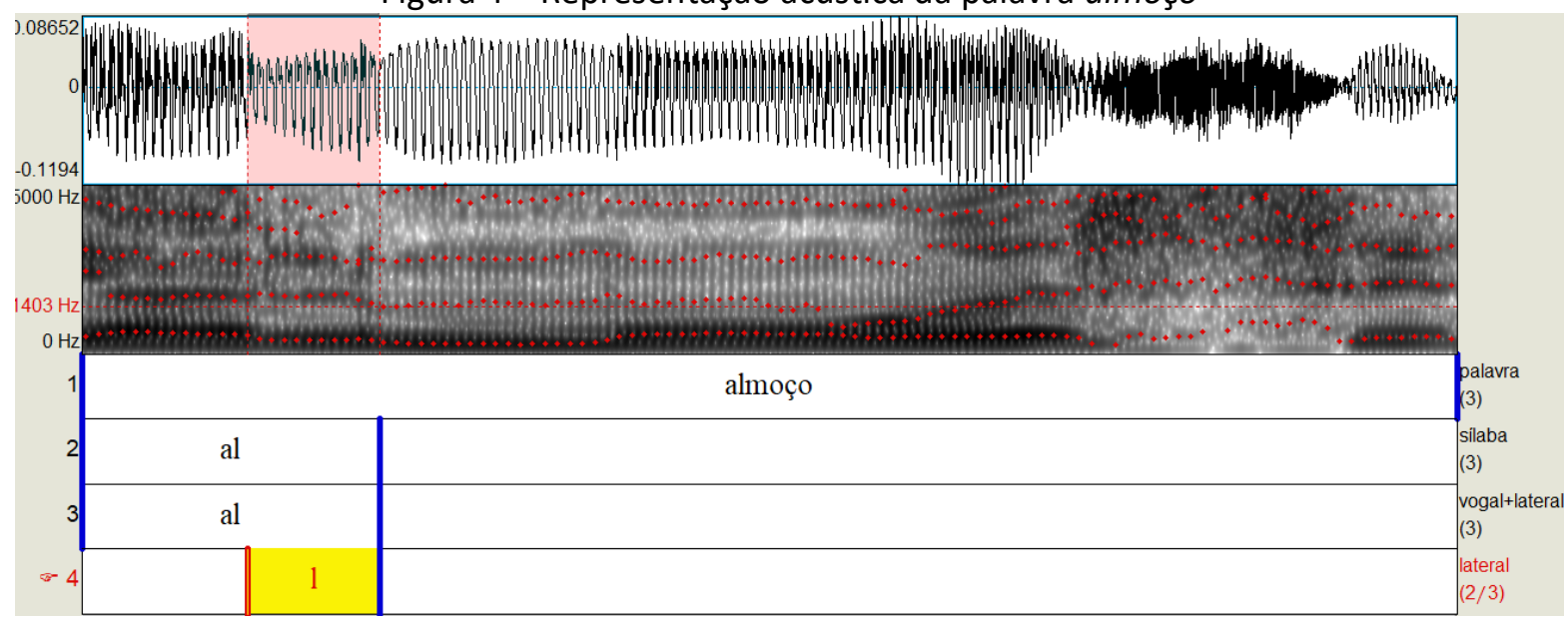

Fonte: as autoras.

A produção de $/ \mathbb{I}$, na palavra almoço, indica sua caracterização como sendo mais anterior. De forma visível no espectro, percebe-se o afastamento entre F2 e F1. Assim, os valores indicados para o primeiro e o segundo formantes confirmam o caráter anterior de /I/ na produção deste vocábulo: $381 \mathrm{~Hz}$ e $1693 \mathrm{~Hz}$, respectivamente.

Conforme apontado por estudos que caracterizam a produção de ///, como Sproat e Fujimura (1993) e Brod (2014), quanto maior é a diferença entre os valores de F1 e F2, mais anterior é a forma de produção de /l/. Esta ampla diferença é vista nas produções da lateral tanto em culto quanto em almoço. Tal caracterização contrasta com a produção mais posterior, cujos valores de primeiro e segundo formantes tendem a aproximar-se. Por isso, nas formas vocalizadas da lateral, não há uma ampla diferença entre os valores de F1 e F2, como pode ser visto na produção da palavra sol, representada na Figura 5, na qual /// apresenta $506 \mathrm{~Hz}$ para o primeiro formante e $1006 \mathrm{~Hz}$ para o segundo formante.

Figura 5 - Representação acústica da palavra sol

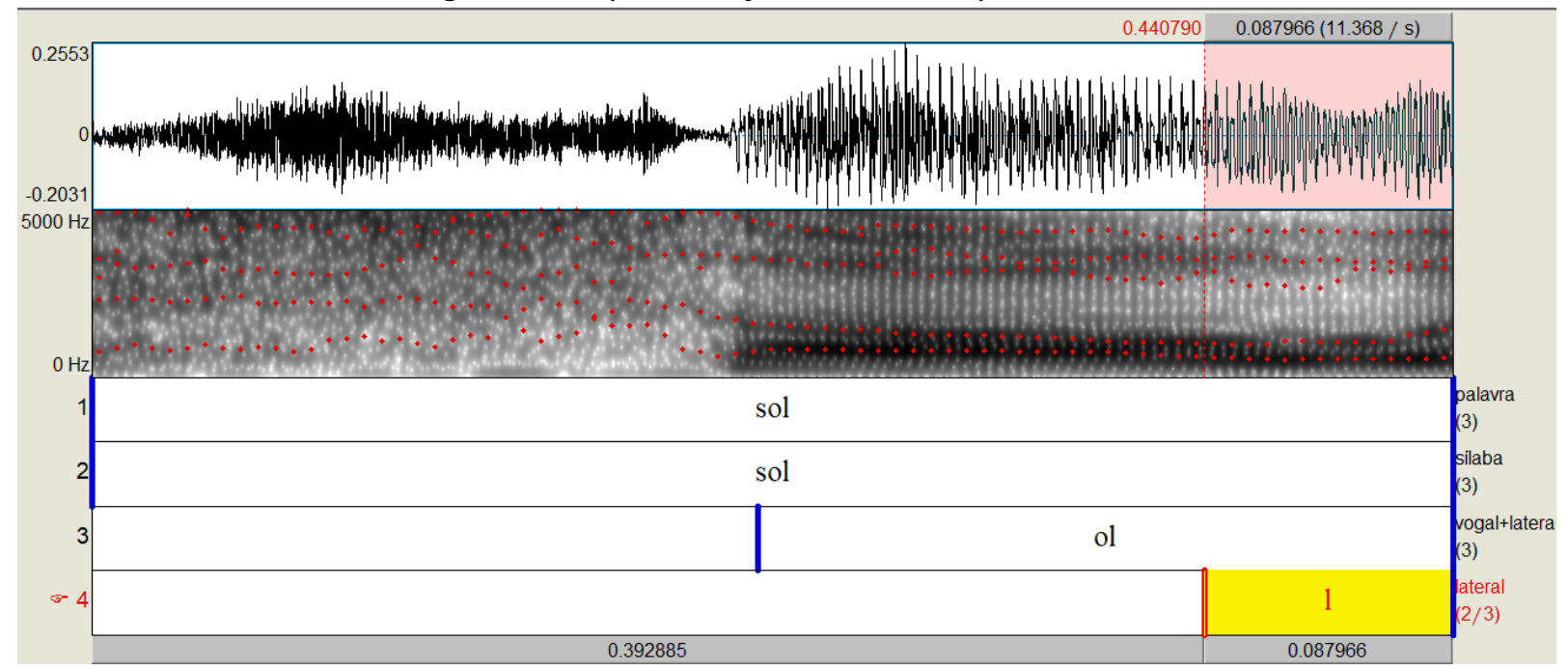

Fonte: as autoras. 
Em se tratando de indícios que distinguem uma produção vocalizada de /I/ da vogal que a antecede, uma maior amplitude de onda chega a ser percebida para a vogal em relação à lateral. Contudo, não há uma distinção evidente, como já indicado, nos valores formânticos. F2 e F1, nesta forma de produção, apresentam um distanciamento que acompanha o distanciamento visto no momento de produção da vogal, o que pode ser observado na representação da Figura 5.

A inspeção acústica exige, muitas vezes, a observação de detalhes sutis de cada produção de um segmento. Nem sempre evidências que distinguem formas mais anteriores de /I/ de uma produção mais posterior são contrastantes entre as produções. Contudo, a observação de um distanciamento entre F1 e F2 que se altera da vogal para lateral, além de ser evidência distintiva entre som vocalizado e consonântico, pode ser tomado como um dos aspectos que aponta uma produção anterior da lateral.

Para a definição dos aspectos articulatórios de /// produzido por sujeito falante de polonês como língua de imigração, são apresentados os traçados da borda do articulador (língua) na realização do movimento de maior magnitude durante a articulação do segmento. Os traçados observados na Figura 6 indicam o posicionamento da língua (direção anterior ou posterior do trato articulatório) no gesto de maior magnitude na produção de $/ \mathrm{I} / \mathrm{em}$ dois tokens da palavra culpa.

Figura 6 - Traçados da borda da língua do ponto máximo de constrição da lateral pós-vocálica nas produções de culpa. Linha verde = culpa1 e linha preta = culpa2. À direita da imagem, parte anterior do trato oral; à esquerda, parte posterior do trato oral

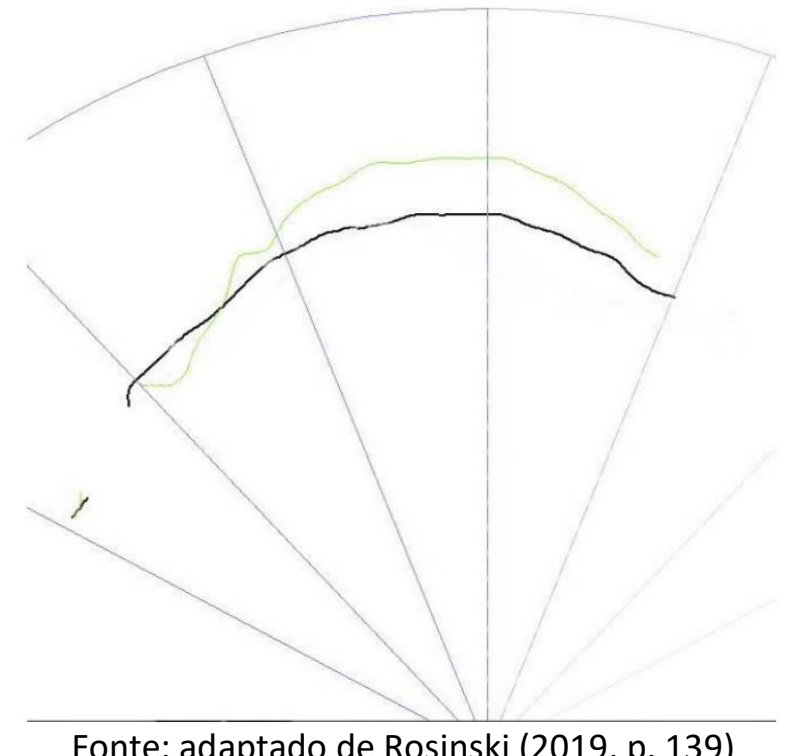

Fonte: adaptado de Rosinski (2019, p. 139)

As realizações da palavra culpa apresentam, para a primeira e para a segunda produção, respectivamente $1221 \mathrm{~Hz}$ e $1415 \mathrm{~Hz}$ de diferença entre os valores do primeiro e do segundo formantes. Acusticamente, os valores formânticos apontam produções mais anteriores de $/ \mathrm{I}$, distanciando-se de uma caracterização que indica a vocalização. $\mathrm{Na}$ observação do movimento de constrição de cada produção, veem-se características 
articulatórias que corroboram tal padrão, pois não há a retração do articulador para a parte posterior do trato articulatório (direção esquerda da representação) - o que seria esperado para uma produção vocalizada do segmento - , apontando que a lateral é produzida com um movimento de ponta de língua. Vê-se, portanto, uma realização anterior de /I/ nas duas produções, ainda que o corpo da língua se eleve um pouco mais para a produção 1 do que para a produção 2.

Na Figura 7, é possível comparar as duas realizações de /I/, em culpa, com uma terceira.

Figura 7 - Traçados da borda da língua do ponto máximo de constrição da lateral pós-vocálica nas produções da palavra culpa. Linha verde $=$ culpa1, linha preta $=$ culpa2 e linha vermelha $=$ culpa3. À direita da imagem, parte anterior do trato oral; à esquerda, parte posterior do trato oral

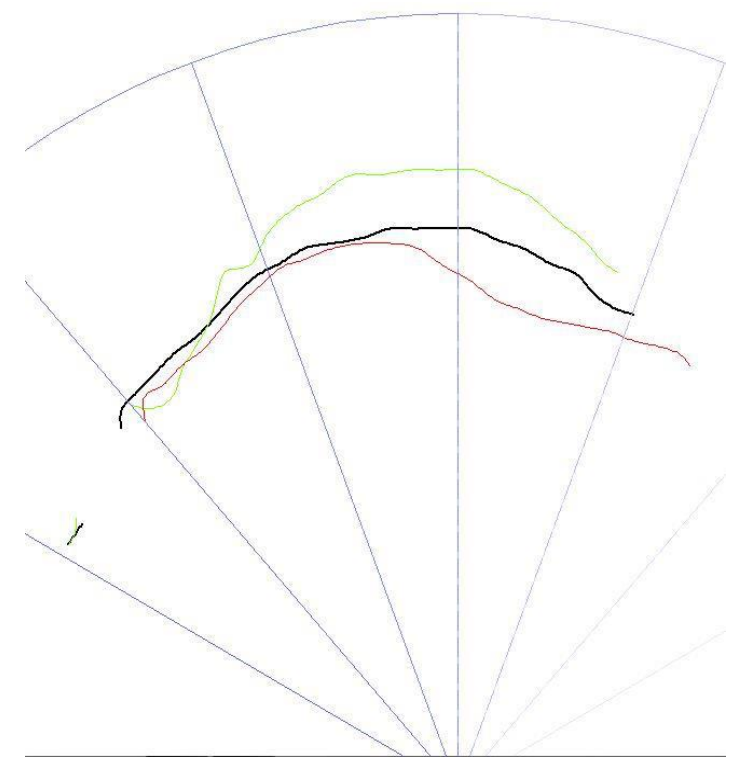

Fonte: Rosinski (2019, p. 139).

Pela linha vermelha, percebe-se uma configuração diferente para o articulador no movimento de contrição máxima da produção de ///. Não há um direcionamento para a parte frontal do trato (direita). De forma contrária, a língua indica realizar apenas um movimento de recuo à parte posterior do trato, mostrando, apesar disso, uma elevação quase idêntica à vista para a realização da lateral em culpa2, já caracterizada como anterior. É importante apontar, na terceira produção de /I/ inserida na comparação, os valores formânticos da diferença F2-F1: $212 \mathrm{~Hz}$, o que representa um valor bem menor em relação ao visto para as outras duas produções.

Os valores obtidos por meio de inspeção acústica para a lateral em culpa3 indiciam uma produção posterior de $/ \mathbb{I}$, caracterização que é apoiada pela sua configuração articulatória. Dessa maneira, vê-se o movimento de retração como definidor principal, pela inspeção articulatória, de uma caracterização mais próxima à vocalização que assume a lateral.

Os dados acústicos e articulatórios da lateral pós-vocálica, aqui reportados, evidenciam, portanto, aspectos fonéticos-fonológicos que configuram as produções 
singulares dos falantes bilíngues português-polonês da comunidade de Costa de Arroio Grande, nas quais perpassam vestígios da língua de imigração e aspectos ímpares da comunidade de fala.

\section{Considerações finais}

O detalhamento fonético das produções de /I/ pós-vocálico, realizado por bilíngues, possibilita identificar características advindas da utilização de polonês como língua de imigração e do próprio português. Por meio das características apresentadas, identifica-se uma lateral que não acompanha aspectos acústicos e articulatórios que o segmento apresenta nas formas mais comumente produzidas no português brasileiro. De forma contrária, os aspectos do segmento mostram-se opostos ao que é visto para o padrão no português - a já mencionada e conhecida tendência à vocalização -, aproximando-se de formas classificadas como velarizadas, observadas em outras comunidades que falam o português gaúcho, vistas nos estudos de Quednau (1993) e Tasca (1999)

Ainda, não apenas reforçando que a lateral produzida por bilíngues distancia-se da produzida por monolíngues, o detalhamento fonético-fonológico permite enxergar os pontos mínimos que concedem a /l/ a caracterização chamada anterior, também referida como menos velarizada.

Pelo detalhamento das características de /I/ produzido por bilíngues, torna-se visível a constituição de uma lateral gerada pelo contato entre português e polonês como língua de imigração. Pode-se inferir que, diferenciando-se do padrão do português, a lateral passa a apresentar características que são vistas na língua polonesa. Esta afirmação toma por base as descrições do segmento feitas por Szreder (2013) e, também, por Swan (2002) e Gussmann (2007), que afirmam o caráter anterior (menos velarizado ou alveolar) da lateral no polonês. No entanto, tratando-se o polonês, neste caso, de uma língua de imigração, transmitida e utilizada em comunidade formada pelos descendentes dos imigrantes, a caracterização das produções de bilíngues, as quais são influenciadas pela língua de imigração, é, de fato, única e diferenciada.

Ao observarem-se as formas orais produzidas pelos bilíngues português-polonês como língua de imigração - neste trabalho, as realizações da consoante líquida lateral do português -, os aspectos vistos são o resultado da coexistência das duas línguas. Deixar de utilizar uma delas (probabilidade evidentemente maior para o caso da língua minoritária) em contexto de comunidade pode interferir na caracterização que, hoje, a inspeção minuciosa, mediada pelas análises acústica e articulatória, possibilitou visualizar.

\section{Referências}

ALTENHOFEN, C. V. Política lingüística, mitos e concepções lingüísticas em áreas bilíngües de imigrantes (alemães) no Sul do Brasil. Revista internacional de lingüística iberoamericana, v. 2, n. 13, p. 83-93, 2004. 
BROD, L. A lateral nos falares florianopolitano (PB) e portuense (PE): casos de gradiência fônica. 2014. 200 p. Tese (Doutorado em Linguística) - Centro de Comunicação e Expressão, Universidade Federal de Santa Catarina, Florianópolis, 2014.

CÂMARA JR. J. M. Estrutura da Língua Portuguesa. Petrópolis: Editora Vozes, 1970.

COLLISCHONN, G.; QUEDNAU, L. R. As Laterais variáveis na região Sul. In: BISOL, L.; COLLISCHON, G. Português do Sul do Brasil: variação fonológica. Porto Alegre: EDIPUCRS, 2009. p. 129-147.

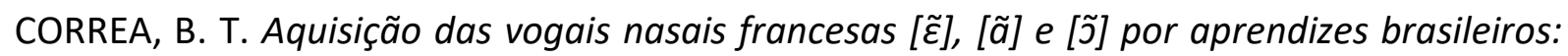
aspectos acústico-articulatórios. 2017. 381 f. Dissertação (Mestrado em Letras). Programa de Pós-graduação em Letras, Universidade Federal de Pelotas, 2017.

DRUSZCZ, A. M. O bilinguismo em Araucária: a interferência polonesa na fonologia portuguesa. 1983. 151 p. Dissertação (Mestrado em Letras) - Curso de Pós- Graduação em Letras, Universidade Católica do Paraná, 1983.

FERRAZ, A. P. O panorama lingüístico brasileiro: a coexistência de línguas minoritárias com o Português. Filol. lingüíst. port., n. 9, p. 43-73, 2007. https://doi.org/10.11606/issn.2176$\underline{\text { 9419.v0i9p43-73 }}$

FERREIRA-GONÇALVES, G.; ROSINSKI, A. A líquida lateral na produção de bilíngues polonês/português. Revista (Con)Textos Linguísticos, v. 11, n. 20, p. 39-53, 2017.

FROSI, V. M.; FAGGION, C. M.; DAL CORNO, G. O. M. Prestígio e estigmatização: dialeto italiano e língua portuguesa da região de colonização italiana do nordeste do Rio Grande do Sul. Revista da ABRALIN, v. 7, n. 2, 139-167, 2017. http://dx.doi.org/10.5380/rabl.v7i2.52493

GUSSMANN, E. The Phonology of Polish. New York: Oxford University Press, 2007.

KAWKA, M. Os brasileirismos do dialeto polono-brasileiro. 1982. 68f. Dissertação (Mestrado) - Universidade Católica do Paraná, Curitiba, 1982.

MILESKI, I. A elevação das vogais médias átonas finais no Português falado por descendentes de imigrantes poloneses em Vista Alegre do Prata - RS. 2013. 152 p. Dissertação (Mestrado em Letras) - Programa de Pós-Graduação em Letras, Pontifícia Universidade Católica do Rio Grande do Sul, Porto Alegre, 2013.

MILESKI, I. Variação no Português de contato com o Polonês no Rio Grande do Sul: vogais médias tônicas e pretônicas. 2017. 321 f. Tese (Doutorado em Letras). Programa de PósGraduação em Letras, Pontifícia Universidade Católica do Rio Grande do Sul, 2017.

NARAYANAN, S.; ALWAN, A.; HAKER, K. Toward articulatory-acoustic models for liquids approximants based on MRI and EPG data. Part I. The Laterals. Journal of the Acoustical Society of America, v. 101, n. 2, p. 1064-1077, 1997. https://doi.org/10.1121/1.418030

OLIVEIRA, G. M. Brasileiro fala português: monolinguismo e preconceito linguístico. In: SILVA, F. L. da; MOURA, H. M. de M. (orgs). O direito à fala: a questão do preconceito linguístico. Florianópolis: Insular, 2000. p. 83-92.

QUEDNAU, L. R. A lateral pós-vocálica no Português gaúcho: análise variacionista e representação não-linear. 1993. 110 p. Dissertação (mestrado em Letras - Língua Portuguesa) - Instituto de Letras, Universidade Federal do Rio Grande do Sul, Porto Alegre, 1993. 
RECASENS, D. Darknesse in [I] as scalar phonetic property: implications for phonology and articulatory control. Clinical Linguistics e phonetics, v. 18, n. 6-8, p. 593 - 603, 2004. https://doi.org/10.1080/02699200410001703556

ROSINSKI, A. A produção da lateral pós-vocálica em uma comunidade bilíngue: aspectos do Português sob a influência do Polonês como língua de imigração. 2019. 179 f. Dissertação (Mestrado em Letras: Aquisição, Variação e Ensino) - Programa de Pós-Graduação em Letras, Centro de Letras e Comunicação, Universidade Federal de Pelotas, Pelotas, 2019.

ROSINSKI, A.; FERREIRA-GONÇALVES. O segmento lateral pós-vocálico do Português sob a influência do Polonês. PAPIA: Revista Brasileira de Estudos do Contato Linguístico, v. 29, n. 1, p. 7-24, 2019.

SILVA, A, H, P. Para a descrição fonético-acústica das líquidas no Português brasileiro: dados de um informante paulistano. 1996. 231 f. Dissertação (Mestrado em Estudos da Linguagem). Instituto de Estudos da Linguagem, Universidade Federal de Campinas, Campinas, 1996.

SPINASSÉ, K. P. Os conceitos de Língua Materna, Segunda Língua e Língua Estrangeira e os falantes de línguas alóctones minoritárias no Sul do Brasil. Revista Contingentia, v. 1, n. 1, p. 1-10, 2006.

SPINASSÉ, K. P. Os imigrantes alemães e seus descendentes no Brasil: a língua como fator identitário e inclusivo. Conexão Letras, v. 3, n. 3, p. 125-140, 2008.

https://doi.org/10.22456/2594-8962.55637

SPROAT, R.; FUJIMURA, O. Allophonic variation in English / $/$ and its implications for phonetic implementation. Journal of phonetics, v. 21, n. 3, p. 291-311, 1993.

https://doi.org/10.1016/S0095-4470(19)31340-3

SZREDER, M. The acquisition of consonant clusters in Polish: a case study. In: VIHMAN, M. M., KEREN-PORTNORY, T. (orgs). The emergence of phonology: Whole-word Approaches and Cross-linguistic Evidence. Cambridge, Cambridge University Press, 2013. p. 343-361. https://doi.org/10.1017/CBO9780511980503.016

SWAN, O. E. A Grammar of Contemporary Polish. Bloomington: Indiana University, Slavica Publisher, 2002.

TASCA, M. A lateral em coda silábica no sul do Brasil. 1999. 174 f. Tese (Doutorado em Letras). Pontifícia Universidade Católica do Rio Grande do Sul, Porto Alegre, 1999.

TURTON, D. Categorical or gradient? An ultrasound investigation of ///-darkening and vocalization in varieties of English. Laboratory Phonology: Journal of the Association for Laboratory Phonology, v. 8, p. 1-31, 2017. https://doi.org/10.5334/labphon.35

WEBER, R.; WENCZENOVICZ, T. J. Historiografia da imigração polonesa: avaliação em perspectiva dos estudos sobre o Rio Grande do Sul. Revista História Unisinos, v. 16, n. 1, p. 159-170, 2012. https://doi.org/10.4013/htu.2012.161.14

Recebido em: 20/04/2020. Aceito em: 21/05/2020. 